\title{
Just say 'no'
}

\section{Clarke}

\section{This is the first article in a series written by a selection of experts who will be speaking at this year's National Dental Conference: Best Practice 2001. In this issue, Mike Clarke explores the problems some patients can cause for dentists.}

$\mathrm{T}$ he vast majority of our patients are quite content to accept our treatment plans. They recognise the dentists' expertise in the field and as a consequence are happy to agree with whatever treatment we suggest.

Just occasionally, however, a dentist can get the feeling that he or she is not necessarily in the pilot's seat, or for that matter, even the co-pilot's. The patient is therefore pushing treatment along - often in the direction the dentist does not want to be.

There are of course times when that simply is not a problem. We have all experienced the denture patient who wants 'little white teeth' and completely ignores the fact that they not only look hideously stupid but actually tend to make the patient look older rather than younger. A dentist in that situation can do no more than advise before agreeing to a patient's request. Generally speaking, the worse that can happen is that you need to remake the dentures with the correct size teeth.

It could be said that some dentists are more prone to this problem than others and certainly in my experience I have come across dentists who freely admit they would rather agree with the patient than argue. Anything for a quiet life? The quiet life, however, comes to an abrupt halt when the letter of complaint is received, or the solicitor's letter alleging negligence arrives.

Take for example the situation where a patient requests that his or her six front teeth should be crowned - perhaps they do not like the size or the shape or even the colour of the teeth. In any event, there are some small restorations but not necessarily enough to warrant preparing the teeth for full crowns.

There is of course the possibility of veneers but the patient tells you that their friend had had these done and they kept falling off. You consider your own success rate with veneers to be not brilliant and decide to agree. Despite your best efforts then the patient is most insistent. Some even suggest that they have spoken to other dentists who had agreed to undertake the treatment but they want you to do it. Obviously you are flattered and like the idea of a private fee for what would, after all, be six fairly straightforward dentine bonded crowns. The idea begins to gel and you agree to undertake the treatment.

With your full consent then you've been sucked in. You decide to cover yourself and take study models for the laboratory to wax up a final result. The patient tweaks a bit here and asks you to lengthen a bit there but agrees. Was it all a little too quick, and a little too easy?

There is of course a nagging doubt in the back of your mind, and you recall those dento legal lectures. You feel duty bound to cover yourself and therefore decide to do these completely by the book. The crown preparations are relatively straightforward and you go to great lengths to explain that these in fact are only temporary crowns and are only designed to be in place in the short term. You also explain that the teeth may be sensitive and that the patient should be extremely careful when biting and chewing. No problem then - the patient's happy. At the fit, the crowns look good and you feel relatively confident that the patient will be pleased with the end result - you are about to make the biggest mistake of your practising career.

It always seems to be the case that no matter how well the crowns are made the patient is never happy. We have all unfortunately heard it: 'This tooth's too pointed.' 'They don't match the colour of the my original teeth' (wasn't that the point of going through this process in the first place!) 'The crowns make my teeth look big.' 'I now have a whistle when I speak'. The possibility for complaint is endless. To make matters worse on permanently rather than using a temporary cement. They are now on there for good.

Your choices are, of course, limited. Starting again is a possibility. Sometimes this works and the patient is satisfied. Frequently, however, the second set of crowns are no better than the first and in desperation you you now realise you cemented the crowns

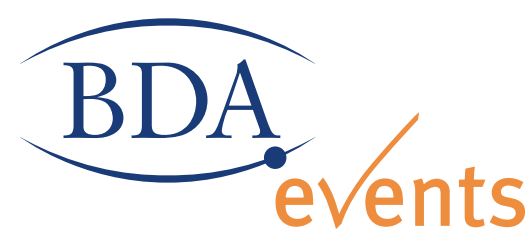

even resort to asking the technician to come down and fabricate the crowns whilst the patient is in the chair. If you are lucky you eventually get them right. More often you reach a compromise with which your patient may be happy (but you frequently are not). The profit element of the crowns has long since gone and you rue the day the patient ever stepped foot in the surgery.

Generally speaking all then goes quiet and you hear nothing more from the patient. Do not be fooled however - you are about to be sucked in and spat out for the second time.

It usually begins with a letter of complaint. 'The crowns you made for me last April have never been right. I continue to get pain and all my friends think they look dreadful.' You are now faced with the prospect of bringing the patient back and trying again, referring to a specialist to see if he can do any better or, perhaps more sensibly, considering refunding the cost of the treatment as a sign of goodwill, thus denting the already diminished profit margin.

If you are brave enough you stand your ground and accept whatever comes. Some patients back down and simply go elsewhere. Others will find a solicitor willing to take the case and given the number of 'ambulance chasing' solicitors available there will be no shortage of takers. If you are really unlucky the patient complains to the General Dental Council and you find yourself writing an enormous number of letters to try and explain why you opted to crown the teeth in the first place.

It is at times like this when you wish you had let your head rule your wallet and you had said 'NO'. So you say, 'this has never happened to you?' - I simply don't believe you.

\section{Best Practice 200 I}

The Conference will take place between 3-5 May 2000 at the Harrogate International Centre. For a copy of the registration formplease contact the Events Office on 02075634590. 